\title{
LA PLANTA DE LA INMORTALIDAD EN GRECIA Y EL MITO DE GLAUCO DE ANTEDÓN
}

\author{
HELENA RodRÍGUEZ SOMOLINOS \\ UNED. Madrid \\ hrodriguez@flog.uned.es
}

\section{RESUMEN}

Algunas notas sobre los orígenes del mito de Glauco de Antedón, en relación con el tema de la planta de la inmortalidad en Grecia.

Palabras Clave: Glauco; Antedón; planta de la inmortalidad, Esquilo.

\section{ABSTRACT}

Some notes on the origins of the myth of Glaucus from Anthedon, in relation with the theme of the plant of immortality in Greece.

KEY WoRDS: Glaucus, Anthedon, plant of immortality, Aeschylus.

El mito de Glauco de Antedón, cuyas primeros testimonios remontan a la obra de Píndaro y de Esquilo, contiene un motivo folclórico y literario muy antiguo, que es el de la planta de la inmortalidad. La inmortalidad, o más a menudo la eterna juventud, reside en una planta que los dioses tienen buen cuidado de ocultar a los hombres mortales. Éstos sólo en ocasiones excepcionales, y siempre por voluntad de un dios, pueden acceder a ella, alterando así el orden establecido entre seres humanos y divinos.

Las líneas generales del mito de Glauco antedonio, en su versión más extendida, son claras: Glauco era un pescador de la ciudad de Antedón en Beocia, que adquirió la in- 
mortalidad tras comer una planta maravillosa y se convirtió en divinidad marina. Las fuentes, más o menos extensas, difieren enormemente sobre su genealogía y aportan todo tipo de detalles y motivos, algunos secundarios y otros importantes como el salto al mar y la adquisición de la capacidad profética, pues Glauco pasa a ser divinidad oracular que se aparece para aconsejar a los navegantes ${ }^{1}$. Glauco comparte características y sobrenombre con otros seres marinos como Proteo o Nereo; probablemente era una versión más del genio marino típicamente egeo. Estos seres suelen ser viejos (de ahí la denominación hálios gérōn «el viejo del mar», no siempre fácil de identificar con exactitud), y a menudo poseen poderes metamórficos y sabiduría oracular.

Por Pausanias (9.22.7) sabemos que la obra de Píndaro mencionaba a Glauco de Antedón ( $F r$. 296), aunque precisa que «la historia no le dió para mucho en sus cantos». Por el contrario, Esquilo compuso un Glauco Marino ${ }^{2}$, del que se conservan algunos fragmentos, que muy verosímilmente era un drama satírico ${ }^{3}$. Sobre su contenido poco podemos saber, salvo que en el comienzo unos boyeros contemplaban aterrorizados cómo Glauco emergía de las aguas con su terrible aspecto ${ }^{4}$, y a continuación el daímon marino les narraba su historia. Dos fragmentos nos hablan de la planta maravillosa; el fr. 28 dice «el que comió la hierba que hace vivir por siempre (aeizōs), que no deja morir (áphthitos)», y de forma similar, en el fr. 29 Glauco en persona es quien afirma «he probado sin duda la hierba que hace vivir por siempre (aeízōs)»5.

El tema de la planta de la inmortalidad irrumpe en la literatura en el Poema de Gilgamesh, como motivo central que justifica las aventuras del héroe y el sentido final del poema. En la tablilla VII muere Enkidu, el amigo de Gilgamesh y éste, al comprender que la muerte es también su destino, decide emprender la búsqueda de la inmortalidad. Tras diversas aventuras, y gracias a la protección del dios Samas y a las informaciones de la tabernera Siduri, logra atravesar el Mar de la Muerte y llegar ante Utnapishtim, único superviviente del Diluvio y también único hombre inmortal, gracias a un don del dios Enlil. En la tabilla XI Utnapishtim, finalmente, revela a Gilgamesh la existencia de la planta maravillosa y le da las instrucciones para conseguirla en las profundidades marinas. Así lo hace el héroe, que se muestra exultante de alegría, pero en un descanso en el camino decide darse un baño en una fuente de agua fresca. Mientras se baña una serpiente sale del agua, atraída por el olor de la planta, y se apodera de ella. Inmediatamente muda la piel.

${ }^{1}$ Aparte de la monografía de Gaedechens 1860, siguen siendo fundamentales los artículos de Weicker en $R E$ XIII, 1408 ss. y de Roscher, Lexikon I.2, 1678 ss. En la bibliografía reciente destacan el artículo de Deforge 1984 y el libro de Corsano 1992, aunque es imprescindible también citar los trabajos de Paladino 1978, Sánchez Jiménez 1991 y sendos artículos de Scherf en Der Neue Pauly IV, p. 109 ss. y de Jentel en LIMC IV.1, p. 271 ss. (Glaukos I).

2 A. Fr. 25a ss. Radt.

${ }^{3}$ Cf. A. Melero en López Férez 1988: 414, 416, y la introducción a dicha obra en la traducción de los fragmentos de Esquilo a cargo de J. M. Lucas, de próxima aparición en la editorial Gredos, y la bibliografía allí citada. Aprovecho para agradecer al profesor Lucas su amabilidad por dejarme consultar diversas secciones del original de esta obra.

${ }^{4}$ Es posible que el Glauco de Esquilo haya influido en las descripciones del dios por Platón (R. 611c-d), Filóstrato (Im. 2.15) y Ovidio (Met. 13.904-14.74).

5 Siguiendo a Deforge 1983 (p. 24 y nn. 2-8), prefiero entender así el adjetivo aeízōn / aeízōon, que otros autores interpretan como «hierba que vive para siempre» (así ya Hsch. s.u. aeízōn). Directamente o no, Nonn.D.13.74 sigue a Esquilo aplicando el adjetivo al propio Glauco, cf. F. Vian, Nonnos de Panopolis, Les Dionysiaques V, París 1995, p. 217. Cf. también DGE III, Madrid 1991, s.u. áphthitos I.2 «que hace inmortal»). 
En Grecia la planta o hierba de la inmortalidad no es exclusiva del mito de Glauco de Antedón, sino que aflora, con nombres y características diversas, aquí y allá en la literatura y la mitología griegas. En primer lugar está presente en los otros dos mitos que tienen a un personaje llamado Glauco como protagonista, y que forman, junto con Glauco de Antedón, un conjunto mítico sumamente interesante que todavía, en mi opinión, dista de estar suficientemente explicado, a pesar de los interesantes trabajos de, entre otros, Deforge 1984 y Corsano 1992. Naturalmente me refiero a Glauco de Potnias y a Glauco hijo de Minos.

En especial el mito de Glauco de Potnias, hijo de Sísifo y rey de Corinto, devorado por sus yeguas, sufre en algunas versiones cruces significativos con el de Glauco de Antedón. Así por ejemplo, según un escolio a Eurípides, la causa del enloquecimiento de sus yeguas fue el haber comido una planta que nacía cerca de Potnias ${ }^{6}$. Pero hay sobre todo una identificación muy clara de ambos personajes en un escolio a Platón, según el cual Glauco era un príncipe hijo del rey de Corinto, Sísifo y de su esposa Mérope, que se convirtió en dios marino. Habiéndose encontrado por azar con la fuente de la inmortalidad, se lanzó a ella con el afán de obtener la condición inmortal, pero, no habiendo podido demostrar a nadie que poseía dicha condición, fué arrojado al mar. Desde entonces Glauco, una vez al año, recorre todas las orillas y las islas, junto a los monstruos marinos, y predice solamente desgracias ${ }^{7}$.

El mito de Glauco, hijo de Minos, al que se reconoce en general un origen cretense, se aparta en algunos motivos de los anteriores, mientras que se aproxima al Poema de Gilgamesh por la conexión entre la planta de la inmortalidad y la serpiente. La historia, que sabemos fue tratada por Sófocles, Eurípides y al parecer por el propio Esquilo en sus Cretenses, se mantiene homogénea en sus fuentes principales, todas ellas tardías ${ }^{8}$. Glauco, hijo de Minos rey de Creta, siendo aún niño cae en una tinaja de miel y muere. Minos, desesperado, consulta los oráculos, y los Curetes —Apolo en alguna versión- le hacen saber que podrá resucitar a su hijo el hombre que sepa resolver un determinado enigma. Lo consigue resolver el adivino Poliido, a quien Minos encierra junto con el cadáver de Glauco. No sabiendo Poliido qué hacer en esta situación, de repente ve aparecer una serpiente. El adivino la mata para proteger el cadáver del niño, pero aparece otra serpiente. Esta ve que la primera está muerta, se marcha y vuelve poco después trayendo una planta con la que la hace resucitar. Poliido coge la hierba, frota el cuerpo de Glauco con ella y así el muchacho resucita.

Muy similar a este mito es el relato sobre el lidio Tilo o Tilón. Esta historia es expuesta por extenso, con una amplia reelaboración literaria, por Nonn.D.25.451-552. Pero gracias a Plinio sabemos que estaba recogida ya en los Lydiaká de Janto de Lidia (siglo $\mathrm{V}$ a.C. $)^{9}$. Sobre su origen se tiende a pensar que es una adaptación local del mito cretense, de origen cultual, de Glauco hijo de $\operatorname{Minos}^{10}$. Aunque en otras fuentes la hierba

6 Sch.E.Or.318.

7 Sch.Pl.R.611d.

${ }^{8}$ En especial Apollod.3.17 ss., Hyg.Fab.136. En el arte el tema aparece ya también desde el V a.C.; cf. O. Palagia en LIMC IV.1, p. 274 Catalogue A I.

9 Xanthos, 765 F 3 Jacoby.

${ }^{10}$ La introducción de Vian (1990: 36 ss.) ofrece un excelente panorama de conjunto, con bibliografía, sobre la historia. 
es llamada balis o ballis, palabra que procede del nombre frigio del rey — es decir, sería la «hierba real»—-en Nonno pasa a llamarse Diòs ánthos «flor de Zeus».

Se ha intentado explicar de diversos modos la presencia en la mitología griega de tres mitos con motivos y elementos comunes tan llamativos: el salto ritual (al mar o a la miel), la oracularidad y sobre todo el nombre del protagonista y la presencia de la planta de la inmortalidad. Para algunos autores, Glauco de Antedón, Glauco de Corinto y Glauco de Creta procederían de una única figura mítica progresivamente diferenciada en personajes diversos, tendiéndose a identificar con esa figura primitiva al Glauco cretense ${ }^{11}$. Deforge 1983 retoma esta línea, considerándolos hipóstasis de un personaje primigenio, que en su caso sería el dios marino, pero atribuyendo a su mito origen cretense. Por su parte, el estudio de Corsano 1992 analiza más que las semejanzas las diferencias rastreables en los tres mitos, insistiendo en que estos tres mitos representan sistemas con funciones y significados propios, y en que son producto de tres contextos histórico-sociales muy distintos. La conexión entre los tres la halla esta autora en considerar que los tres mitos reflejan procesos iniciáticos, es decir, son mitos que reflejan el paso de una condición a otra. En cuanto al nombre, esta autora intenta relacionarlo con el carácter de los personajes, que se muestran capaces de superar las pruebas necesarias para llevar a buen fin su «paso», su cambio de estatus.

El análisis detallado de los textos y de los motivos presentes en los tres mitos permite a Corsano desarrollar una argumentación muy convincente en lo que respecta al carácter de los tres mitos como mitos «de paso». Menos convincente resulta la interpretación del nombre Glauco «Brillante» como una característica del carácter positivo de los personajes. Aunque adquiriera pronto la noción del brillo, en origen el adjetivo glaukós no significa «brillante» sino «gris azulado»o «azul pálido» ${ }^{12}$. Pero sobre todo, resulta muy difícil prescindir del hecho de que Glaukos es un nombre sumamente apropiado para un dios del mar, ya que a menudo los seres marinos portan nombres relacionados con características del $\operatorname{mar}^{13}$, y desde Homero el adjetivo glaukós se aplica frecuentemente al mar ${ }^{14}$.

De otro lado, Corsano presta escasa atención al tema de la inmortalidad, cuando el mito de lo que nos está hablando es precisamente de ella, y pasa rápidamente sobre el tema de la planta, siendo como es uno de los motivos más significativos de entre los que comparten los tres mitos. Además, establece una clara diferencia entre la planta dadora de inmortalidad de Glauco Marino y la planta dadora de vida, con capacidad de resucitar, de Glauco cretense. Sin embargo, se trata sin duda de la misma planta.

Hemos visto los dos versos de Esquilo que mencionan la hierba «que hace vivir por siempre». Ateneo (296 ss.) menciona diversos autores que trataron el tema de Glauco de Antedón, presentando curiosas versiones alternativas, algunas de las cuales mencionaremos después ${ }^{15}$. Entre estos autores cita dos fragmentos que amplían nuestra información sobre la planta. El primero es de Alejandro Etolo (Alex.Aet.1), quien dice que

${ }^{11}$ Cf. Corsano (1992: 1 ss.) y la bibliografía allí citada.

12 Cf. Chantraine, DELG s.u., Maxwell-Stuart 1981, Pötscher, 1998.

13 Cf. las nereidas Glauca y Glaucónome desde Hes. Th. 244, 256.

${ }_{14}$ Il.16.34, cf. DGE IV s.u. I. La misma forma sustantivada glaukē denomina al mar en Hes. Th.440.

15 Otras fuentes importantes sobre Glauco Marino son Paus.9.22.7, Ou.Met.13.904 ss., Philostr.Im.2.15.4 ss., Eust.271.16 ss., Sch.A.R.1.1310a y Sch.E.Or.318, que cuentan la historia por extenso. Plutarco (Cic.2.3), cuenta que Cicerón había compuesto, siendo todavía niño, un poemita llamado Glauco Marino, tras ser discípulo de Arquias. 
Glauco se lanzó al mar tras probar la hierba ... «... que para el Sol resplandeciente hace crecer en primavera la tierra en las islas de los bienaventurados». Además el texto dice que esta hierba la ofrece el Sol a sus caballos para que puedan completar cada día su recorrido sin dejarse vencer por el cansancio. El segundo fragmento es un verso de Escrión de Samos, lírico del IV a.C., en el que alguien se dirige a Glauco diciéndole: «y encontraste la hierba de los dioses, que plantó Crono» (Aeschrio SHell.5). Así pues es una hierba divina, procedente de los tiempos primigenios.

Deforge 1983 ha mostrado, en mi opinión convincentemente, que esta «plante miraculeuse qui modifie le destin humain, qui redonne la vie, qui donne même l'immortalité» (p. 32) se aproxima enormemente a la ambrosía, el alimento de los dioses por excelencia. Como demuestran algunos episodios míticos examinados por Deforge, la ambrosía no es un privilegio de los dioses, sino un elemento indispensable para su condición inmortal, que los diferencia de los humanos. Por ello la protegen cuidadosamente, intentando evitar que los mortales se apoderen de ella, introduciendo así alteraciones en el orden establecido. Por esta razón Zeus castiga a Tántalo, que ha entregado el néctar y la ambrosía a los hombres (Pi.O.I.59 ss.). Por ello el mismo Zeus intenta evitar que los gigantes se apoderen del phármakon que los podría hacer inmortales y por tanto invencibles (Apollod.1.35). Y para evitarlo el padre de los dioses tòn phármakon éteme «cortó la droga», expresión que delata que esta droga es una planta. La conclusión de Deforge es clara:

Apoyándonos en este texto, podemos decir que, al menos en una tradición, la ambrosía, alimento de los dioses defendido por ellos celosamente desde los tiempos primordiales porque es la condición de su inmortalidad, es una hierba. Y la hierba de Antedón, si no se identifica con ella, es por lo menos un esqueje (p. 35).

Podríamos apoyar esta idea con otro testimonio sobre un phármakon que preserva la juventud, que Zeus esta vez concede voluntariamente en signo de agradecimiento. Se halla en un relato etiológico (explica por qué los hombres no son inmortales y por qué las serpientes mudan la piel), transmitido por Eliano ( $N A$ 6.51) que acabó derivando en fábula, y que parece depender de forma bastante directa del relato del Poema de Gilgamesh ${ }^{16}$.

Irritado Zeus por el robo del fuego por parte de Prometeo, entregó como premio a los que le denunciaron una droga contra la vejez (phármakon gèrōs amyntèrion). Ellos la pusieron sobre un asno y emprendieron el camino con él. Era tiempo de verano y el asno quiso beber en una fuente; pero la serpiente rechazaba al asno, no quería dejarle beber. Entonces hubo un acuerdo: el asno dio la droga a la serpiente a cambio de que le dejara beber. Así se hizo: el asno bebió y la serpiente mudó su piel (gēras), quedándose también con la sed del asno.

Si tenemos en cuenta los testimonios aportados por Deforge de un lado, y la conexión con el Poema de Gilgamesh de otro, podemos concluir que también este phármakon es una planta, un testimonio más de la hierba maravillosa que guarda el secreto de la inmortalidad de los dioses, y que sólo algunos mortales excepcionales como Glauco de Antedón y Glauco de Creta llegan a disfrutar.

${ }^{16}$ Cf. Adrados 1987, de quien tomo la traducción, y sobre sus paralelos folclóricos y míticos cf. Davies 1987. Eliano dice que el tema fue tratado, entre otros autores, por Íbico y Sófocles. 
Un detalle excepcional en ambos mitos - $-\mathrm{y}$ en la versión del mito de Glauco de Potnias en que las yeguas enloquecen por comer la planta- reside en el hecho de que la planta no les ha sido ofrecida por un dios, sino que entran en contacto con ella por azari ${ }^{17}$. Lo cual tiene consecuencias negativas, pues es privilegio de los dioses el poder conceder los poderes de la planta en determinadas situaciones excepcionales. E incluso en estos casos, en general el proceso de adquisición de la inmortalidad por parte de mortales no suele completarse de forma satisfactoria. Como bien detalla Corsano, a menudo se trata de una inmortalidad imperfecta (p. 14 ss.). Un ejemplo paradigmático es el de Titono, a quien Zeus, por petición de Eos, concedió la inmortalidad pero no la eterna juventud, lo que a largo plazo tuvo consecuencias terribles para el amante de la Aurora. El caso de Glauco tiene puntos en común con el de Titono, pues algunas fuentes nos dicen expresamente que al comer la planta, Glauco adquirió la inmortalidad pero no dejó de envejecer. Sólo al llegar eis ákron gērōs «a la vejez extrema» saltó al mar, pasando a convertirse en thalássios daímōn ${ }^{18}$.

En cuanto al origen del mito, la bibliografía no se extiende demasiado, más allá de las generalidades que hemos mencionado en su relación con los otros Glaucos. Suele encontrarse aquí y allá la idea de que el mito de Glauco, en la versión más conocida, que es la que encontramos a partir de Esquilo, es originario de la ciudad de Antedón, sin precisar mucho más. Es muy probable que así sea, y en las próximas líneas intentaremos reforzar esta idea.

Centrada en defender la elaboración independiente de los tres mitos protagonizados por un Glauco, en contextos histórico-sociales también independientes y muy diversos entre sí, Corsano 1992 no ve justificado el buscar relaciones de orden genético (p. 188). Sin embargo, es indudable que hay relación entre los tres mitos, y por tanto por fuerza han de existir esas relaciones de orden genético dentro de una progresión temporal, aunque por supuesto es muy difícil, diríamos imposible, establecer tanto las unas como la otra.

Lo único que a este respecto podemos aportar es la sospecha de que la versión más extendida del mito de Glauco de Antedón representa una fusión reciente de elementos antiguos, o al menos una fusión secundaria de elementos anteriores. A esta sospecha se une otra: la de que el mito es una elaboración propia de la ciudad de Antedón, que sólo gracias a la obra de Esquilo alcanzó una amplia difusión, quedando como la versión standard del tema.

La prueba más clara de que hay una reelaboración por parte de la ciudad de Antedón de un tema mítico preexistente está en el nombre de la ciudad. En su artículo de la Realencyclopädie, Weicker exponía la idea de que el mito procede de Atendón, partiendo de la idea de una explicación etimológica del nombre Anthēdon: «La leyenda cultual enlaza con la interpretación etiológica del nombre de la ciudad de Antedón, en una flor maravillosa que en un tiempo creció allí, cuyo disfrute otorgaba la inmorta-

\footnotetext{
17 Alguna versión intenta subsanar esta anomalía, como la

18 Sch.A.R.1.1310a «Tomando ( $s c$. la planta) Glauco, la comió y él mismo fue divinizado. Después, cuando llegó a la vejez extrema, no pudiendo soportarla saltó al mar y fue honrado como divinidad marina», cf. Sch.E.Or.364 «comiéndola también él (sc. la planta) pasó a ser inmortal, pero no carente de vejez, por lo cual se arrojó al mar», Sch.Lyc.754, etc.
} 
lidad (an eine einst dort wachsende Wunderblume an, deren Genuss Unsterblichkeit verleiht $\left.{ }^{19}\right)$.

Es decir, para Weicker el nombre de Antedón sería un compuesto de ánthos «flor» y hédomai «disfrutar», y nos estaría hablando de «el que disfruta de las flores», «el que se regocija en las flores». Naturalmente, éste no podría ser sino Glauco, que alcanzó la condición divina y la inmortalidad por medio de una planta maravillosa. Otros autores, como Corsano, toman en consideración sólo la primera parte del nombre, identificando en él sólo el elemento ánthos «flor», e interpretando Antedón como «la ciudad de la flor» (p. 188s.)

Personalmente creo que es más oportuno considerar que la localización del mito en Antedón se debe a un proceso de etimologización del nombre de la ciudad, probablemente pregriego, como compuesto de ánthos y de la raíz de édomai «comer» ${ }^{20}$. Es decir, Antedón sería la ciudad del que comió la flor, y Glaukos Anthèdónios sería «Glauco el que comió la flor». Desde el Poema de Gilgamesh la planta de la inmortalidad se debe comer para que transmita sus maravillosos dones (tablilla XI, 280 «la llevaré a la amurallada Uruk, haré que coman la planta»; 283 «yo mismo la comeré y así volveré al estado de mi juventud». Y las fuentes griegas insisten repetidamente en el hecho de que Glauco comió la planta ${ }^{21}$, quizá reforzando voluntariamente esta interpretación del nombre de la ciudad.

Que esta «etimología» subyace a la localización del mito en Antedón se demuestra por el hecho de que anthēdōn como nombre común califica a un tipo de abejorro «que come de las flores» ${ }^{22}$. Que a su vez parece una etimología popular a partir de relacionar anthrēdōn con ánthos (así en D.S.17.75) ${ }^{23}$.

En segundo lugar, podríamos aducir que hay otras versiones del paso de Glauco a la inmortalidad, en las que no interviene ninguna planta. Así, en el historiador helenístico Posis de Magnesia (FGH 480 Fr.2) el salto al agua y la divinización de Glauco son consecuencia exclusivamente de la voluntad de Zeus. Glauco aparece aquí como constructor y piloto de la nave Argo, cuando Jasón se enfrenta a los tirrenos. Siendo el único que sale indemne de la batalla naval, desaparece por voluntad de Zeus en las profundidades del mar, convirtiéndose en dios marino que sólo es visto por Jasón. Por su parte, el ya mencionado escolio a Platón (Sch.Pl.R.611d) transmite una versión del mito, quizá de origen Corintio, según la cual Glauco es un príncipe de Corinto que, habiendo encontrado por azar la fuente de la inmortalidad, se lanza a ella con el afán de obtener la condición inmortal. Como hemos visto, también esta inmortalidad fue incompleta, pues nadie le creyó y por ello fue arrojado al mar. Convertido en genio marino maléfico, a diferencia de

19 Weicker en $R E$ cols.1408-9, cf. Hild en Daremberg-Saglio, DAGR II.2, 1611, Sánchez Jiménez 1991, p. 180 y n. 5

${ }^{20}$ Aunque no hay verdaderos compuestos de esta raíz en -ēdon, sí hay algún segundo elemento de compuesto real con vocalismo largo, como ómēstēs «que come carne cruda», epíteto de Dioniso; cf. Chantraine, DELG s.u.éd (p. 313).

${ }^{21}$ Prácticamente todas las fuentes que hemos visto y otras: A.Fr.28-19, Paus.9.22.7, Philostr.Im.2.15.4 ss., Nonn.D.35.73 ss., Sch.A.R.1.1310a, Sch.E.Or.318, Eust.271.16 ss., etc. Naturalmente, cuando la función de la planta es revivir un cadáver, no es posible cumplir esta premisa, por lo que la planta se debe frotar contra el cuerpo, como en el relato de Glauco cretense, o acercar a la nariz, como en el relato nonniano de Tilo.

${ }^{22}$ Cf. DGE II s.u. 2.

${ }^{23}$ Como afirma Chantraine 1933, p. 361. 
Glauco de Antedón, recorre una vez al año las orillas y las islas, junto a los monstruos marinos, y predice desgracias.

Curiosamente, en ninguna de estas dos versiones, que ignoran la planta de la inmortalidad, el mito se sitúa en Antedón. El relato de Posis ofrecido por Ateneo calla sobre su origen, y en el escolio a Platón Glauco procede de Corinto.

A excepción de estas dos tradiciones, todas las demás fuentes relacionan a este Glauco, convertido en divinidad marina gracias a la planta, con la ciudad de Antedón. Una conclusión posible es que sólo la «etimologización» que proponemos del nombre de Antedón habría hecho intervenir la ingestión de la hierba de la inmortalidad en el paso de Glauco a divinidad marina, al mismo tiempo que situaba el mito en esta ciudad. Por el contrario, las otras dos versiones, anteriores o derivadas de versiones anteriores ${ }^{24}$, conservan el salto ritual al mar como único paso previo a la conversión de Glauco en daímōn marino.

Pausanias (9.22.7) nos dice que Píndaro y Esquilo aprendieron este relato de los habitantes de Antedón. Quizá no podamos tomar esta afirmación al pie de la letra, aunque la esencia de la información que nos da ofrece bastante verosimilitud a la luz de lo expuesto. En tal caso habría sido Esquilo, al recoger y desarrollar esta versión local en su Glauco marino, el responsable de la amplia difusión del mito y del personaje desde el siglo V a.c. (recordemos que Glauco no aparece antes en la literatura ni de forma inequívoca en el arte). Como en otras ocasiones, el tratamiento recibido por un tema mítico en la tragedia habría sido determinante en la forma posterior de dicho tema, así como en su difusión más allá de su contexto originario.

\section{REFERENCIAS BIBLIOGRÁFICAS}

Adrados, Francisco R. (1987): «Íbico 62 y el influjo del Gilgamés en Grecia», Aula Orientalis 5, 5-9.

Chantraine, Pierre (1933): La formation des noms en grec ancien. París.

Chantraine, Pierre, DELG: Dictionnaire Étymologique de la Langue Grecque. Histoire des mots, París $1999^{2}$.

Corsano, Marinella (1992): Glaukos. Miti greci di personaggi omonimi. Roma.

DAREMBERG, Charles - SAGLIO, Edmond: DAGR: Dictionnaire des Antiquités grecques et romaines. París 1887-1919.

DAVIES, Malcolm (1987): «The ancient Greeks on why mankind does not live forever», $M H$ 44, 65 -75 .

Deforge, Bernard. (1983): «Le destin de Glaucos ou l'immortalité par les plantes», en F. Jouan (ed.), Visages du destin dans les mythologies. Mélanges Jacqueline Duchemin, París, pp. 21-39.

DGE: Diccionario Griego Español. Madrid 1980 ss.

Der Neue Pauly: Der neue Pauly. Enzyklopädie der Antike hgg. von H. Cancik und H. Schneider. Stuttgart - Weimar 1996-2003.

GAEDECHENS, Rudolph. (1860): Glaukos der Meergott. Gotinga.

LIMC: Lexicon Iconographicum Mythologiae Classicae. Zurich, Munich, 1981-1999.

${ }^{24}$ Corsano 1992 considera ambas tradiciones como sendas elaboraciones de Magnesia del Meandro, ciudad natal de Posis, y de Corinto; cf. p. 96 ss. 
LóPEZ FÉREZ, Juan Antonio (1988): Historia de la Literatura Griega, Madrid.

MAXWELl-Stuart, Peter G. (1981): Studies in Greek colour terminology, I : Glaukós. Leiden.

PAlADINO, Ida (1978): «Glaukos, o l'ineluttabilità della morte», SSR II, pp. 289-303.

PÖTSCHER , Walter (1998): «Glauke, glaukos und die Bedeutung von glaukos», RhM. 141, pp. 97111.

RE XIII: Paulys Realencyclopädie der classischen Altertumswissenschaft XIII (Fornax bis Glykon). Stuttgart 1910.

ROSCHER, Lexikon: Ausführliches Lexikon der griechischen und römischen Mythologie hgg. von W.H. Roscher. leipzig 1886-1924 [Hildesheim 1965].

SÁNCHEZ JiMÉNEZ, Francisco (1991): «Dioniso, Ariadna y la desdicha de Glauco», Baetica 13, pp. $177-189$.

VIAN, Francis (1990): Nonnos de Panopolis, Les Dionysiaques tome IX, Chants XXV-XXIX. París. 